\title{
Individual and context correlates of the oral pill and condom use among Brazilian female adolescents
}

Ana Luiza Vilela Borges ${ }^{1,2^{*}}$ (D), Luciane Simões Duarte ${ }^{1,2}$, Alejandra Andrea Roman Lay ${ }^{3}$ and Elizabeth Fujimori ${ }^{1}$

\begin{abstract}
Background: Studies have examined the impact of contextual factors on the use of contraceptives among adolescents and found that many measures of income and social inequality are associated with contraceptive use. However, few have focused on maternal and primary health indicators and its influence on adolescent contraceptive use. This paper assesses whether maternal mortality rates, antenatal care visits, and primary healthcare coverage are associated with pill and condom use among female adolescents in Brazil.

Methods: We used data from the Study of Cardiovascular Risks in Adolescents (ERICA), a national, school-based cross-sectional study conducted in Brazil. A subsample of all female adolescents who had ever had sexual intercourse and were living in one of the 26 State capitals and the Federal District was selected $(n=7415)$. Multilevel mixed effects logistic regression models were estimated to examine the effect of contextual variables on pill and condom use.

Results: Sixty-five percent of female adolescents reported using pill while $21.9 \%$ reported using condom during the last sexual intercourse. Adolescents living in municipalities with low maternal mortality and high antenatal care coverage were significantly more likely to use pill during the last sexual intercourse compared to those from municipalities with high maternal mortality and low antenatal care coverage. Primary healthcare coverage (proportion of the population covered by primary healthcare teams) was not significantly associated with either condom or pill use during the last sexual intercourse.
\end{abstract}

Conclusion: Our findings suggest that promoting the use of pill among female adolescents may require approaches to strengthen healthcare systems rather than those focused solely on individual attributes.

Keywords: Female adolescents, Pill and condom use, Individual and contextual factors, Multilevel analysis, Brazil

\section{Background}

Unintended pregnancies among adolescents remain a relevant public health challenge worldwide, especially in low and middle-income countries, where almost half of the pregnancies in individuals aged 15-19 years are estimated to be unintended [1]. In these countries, only

\footnotetext{
*Correspondence: alvilela@usp.br

1 Public Health Nursing Department, School of Nursing, University of São Paulo, São Paulo, Brazil

Full list of author information is available at the end of the article
}

one-third of sexually experienced females aged 15 to 19 use contraceptive methods [2].

There is substantial heterogeneity in adolescent contraceptive use across and within countries. However, adolescents mainly use short-acting methods, such as condoms and pills [1,3-5]. Condoms are generally promoted among young people to prevent pregnancy and sexually transmitted infections (STIs), for example, HIV/AIDS. Condoms are widely available; providers often offer condoms instead of long-acting hormonal contraceptives 
(LARCs) because of a misconception that some LARCs are not appropriate for nulliparous women [6]. This situation may increase adolescents' preference for condoms, at least in sporadic relationships, or at the beginning of new ones [7]. Several studies have demonstrated that the use of condoms during the last sexual intercourse differs among regions and countries and ranges from far less than $20 \%$ in many African and Latin-American countries $[8,9]$ to $74 \%$ in some European countries [10].

Worldwide, the prevalence of pill usage by adolescents is lower compared with condoms, ranging from 1 to $12 \%$ in Africa and South America, respectively [1], to $24 \%$ in Europe [10]. In general, female adolescents face many barriers to accessing oral contraceptives, because a common requirement to obtain them is a medical prescription, and specific policies and programs issued by governments limit girls' access [6].

Cross-regional and -national differences in condom and pill use among adolescents have been explained by contextual factors, such as the sexual education programs at schools, availability of adolescent health services, and quality and access to family planning services and supplies [11]. Such contexts have often been ignored in investigations of adolescent contraceptive behavior, which have tended to focus on individual aspects, for example, age, socioeconomic status, behaviors such as alcohol use, and exposure to violence. Notably, the interventions that focus only on the individual level are likely to have a limited impact on contraceptive behavior [12]. Some studies that have examined the impact of contextual factors on the use of contraceptives have found that many measures of inequality, such as the Human Development Index and Gini coefficient, as well as poverty and investments in education, are associated with contraceptive use, especially condoms $[13,14]$.

Identifying contextual characteristics associated with individual practices could guide the implementation of effective family planning programs tailored to adolescent contraceptive needs [13]. Thus, our objective was to assess individual and contextual factors that influence the use of oral pill and condoms among Brazilian female adolescents. Our hypothesis is that female adolescents living in municipalities that present a better performance in some health indicators are more likely to use a condom or pill at the last sexual intercourse than their peers living in municipalities with inadequate performance on these indicators.

In the Brazilian context, $80 \%$ of adolescents report the use of contraceptive methods at the last sexual intercourse $[15,16]$. While male condom was used by $69 \%$ of the adolescents, with no statistical difference by type of school (public/private) or region of residence, the use of pill was reported by only $13 \%$, with significant differences between the regions [15]. Although male condoms are widely available in primary healthcare facilities, pills are available only with medical prescription in such contexts. The purchase of oral contraceptives without medical prescription is a common practice in the country, though not allowed. LARCs are rarely reported in Latin America and the Caribbean, including Brazil [17, 18].

\section{Method}

\section{Study design}

This study uses data from the Study of Cardiovascular Risks in Adolescents (ERICA). ERICA is a cross-sectional study carried out to assess the prevalence and covariates of cardiovascular risk factors in adolescents. It also assessed some other characteristics of adolescents' lives, such as contraceptive practices.

\section{Sample and setting}

The sample included male and female adolescents aged 12 to 17 years who attended public and private schools in 2014. The ERICA sampling design comprised all Brazil's state capitals, the Federal District, and groups of other municipalities of more than 100,000 residents (large cities) from the macro-regions of the Country (North, Northeast, East-center, Southeast, and South). A sample of 1,251 schools was selected across all strata with probability proportional to size. In each school, three classes covering seventh to ninth grades in elementary school and from first through third grades in high school were randomly selected, and all adolescents from the selected classes were invited to take part in the research. Exclusion criteria and other details about the sample design are found elsewhere [19]. In total, 75,060 adolescents were included in the ERICA study.

The questionnaire for adolescents (available in English in Additional file 1) was self-administered using an electronic personal digital assistant [20].

We aimed to explore the individual and contextual influences related to the use of contraception at the last sexual intercourse. The focus was on female adolescents who had ever had sexual intercourse $(n=7415)$ living in one of the capitals and the Federal District.

\section{Procedures and variables}

Multilevel logistic models with mixed effects were estimated to evaluate individual and contextual factors related to the use of the pill $(n=1629)$ or a condom $(n=4841)$ at the last sexual intercourse. Individual factors included age $(12,13,14,15,16$, and 17 years); skin color (white and non-white; non-white comprises respondents who self-reported as Black, mixed, Asian and Native Indian); family structure (living with parents, mother only, the father only, and none (i.e., can include 
other adult or a partner); mother's education (low from illiterate to less than 8 years of schooling; middle from 8 to 11 years of schooling, high -12 or more years of schooling); type of school (public and private), paid jobs (no and yes), and age at sexual onset (until 14 years or 15 years and older).

Context variables were health indicators such as primary healthcare teams' coverage, antenatal care coverage, and maternal mortality rate (MMR). Brazil is a country of continental dimensions with widespread regional and social inequalities. The country`s MMR has substantial regional disparities that reveal socioeconomic differences and inequalities in access to healthcare [21]. Regarding antenatal care coverage, there has been improvement in recent years, but there are still inequalities in access, with marked differences in the timing of the first visit and the number of visits across regions [22].

The variable primary healthcare coverage was measured by the percentage of the population covered by family health teams. A physician, a nurse, two nurse assistants, and four to six health community workers compose family health teams in Brazil, which is part of the Family Health Strategy. The Family Health Strategy was launched in 1994 to provide primary healthcare and improve health indicators in lower-income families. In 2014, the same year of our fieldwork, Brazil had approximately 39,000 family health teams: more than 265,000 community health workers serving 120 million people (62\% of the population) [23]. Municipal-level analyses suggested that the strategy showed positive effects on health indicators, such as infant mortality, especially through the reduction of diarrhea- and pneumoniarelated deaths [24]. Each health professional in the team has clear roles and tasks focused on responding to the most prevalent health problems and needs, including the provision of family planning services. The coverage of primary healthcare teams was calculated considering that each family health team is responsible for 3000 individuals residing in a geographical area close to a primary healthcare facility. The coverage of primary healthcare teams was analyzed in tertiles (1st tertile - municipalities whose coverage of primary healthcare teams was $27.4 \%$ to $50.7 \%$; 2nd tertile - municipalities whose percentage was $52.3 \%$ to $64.0 \%$; and 3rd tertile - municipalities whose percentage was $67.6 \%$ to $100.0 \%$ ).

Within the range of reproductive health care, antenatal care ensures better maternal and infant outcomes [25]. Currently, high antenatal care coverage is captured through the number of visits [26]. The recommended antenatal care model of four visits was increased to eight visits for the entire period of pregnancy to guarantee increased opportunities to detect and manage potential problems [25]. In our study, high antenatal care coverage was measured by the percentage of newborns with more than seven antenatal care visits in 2013 - irrespective of whether the source of care was private or public services - because this is the minimum number of visits recommended by the Brazilian Ministry of Health [27] and this is how the information is available from the Information System on Live Births. We analyzed high antenatal care coverage in tertiles (1st tertile - municipalities whose percentage of newborns with more than seven antenatal care visits was $33.8 \%$ to $51.3 \%$; 2nd tertile - municipalities whose percentage $64.6 \%$ to $70.2 \%$; and 3rd tertile municipalities whose percentage was $70.4 \%$ to $88.1 \%$ ).

The monitoring of MMRs was relevant because MMR is an indicator of the performance of health services; thus, high rates are associated with poor quality of women`s health services, including family planning, antenatal, childbirth, and postpartum care [28]. The 2013 MMR of each capital was calculated from the Mortality Information System and the Information System on Live Births available at DATASUS (Information Technology Department of the Brazilian Public Healthcare System) (http://www2.datasus.gov.br/DATASUS/index.php? area $=02$ ). To calculate MMR, births and maternal deaths were adjusted using adjustment factors used by the Ministry of Health [29] to minimize the underreporting of maternal deaths. In Brazil, the MMR is high - approximately 60 maternal deaths per 100,000 births [29] - and unequally distributed among geographical macro-regions [30] due to inequalities in access to high-quality healthcare services, high rates of C-sections, and restrictive abortion laws. The MMR was analyzed in tertiles (1st tertile - municipalities whose MMR was 27.8 to 50.3 deaths per 100,00 births; 2nd tertile - municipalities whose MMR was 53.3 to 79.7 ; and 3rd tertile - municipalities whose MMR was 88.3 to 165.7 ).

Contextual factors were captured in 2013 and 2014, and pertain to the period before the interviews with students.

\section{Statistical analysis}

All analyses were conducted using Stata ${ }^{\circledR}$ software version 14.0 and took into account sample weights. We present the distribution of all female adolescents who had ever had sexual intercourse as well as those who used pill or condom during the last sexual intercourse by background characteristics.

We then estimated multilevel mixed-effects logistic regression models to examine the association between individual- and context-level factors and use of pill or condom during the last sexual intercourse, taking into account clustering of female adolescents at the municipality level.

We present (1) the empty model to obtain the variance attributed to the municipality, (2) the unadjusted models, 
(3) the association of all individual-level variables with each outcome (Model 1), and (4) the final model, that included both individual- and context-level factors. We present the crude and adjusted odds ratios with 95\% confidence intervals $(95 \% \mathrm{CI})$. Estimates with p-values less than 0.05 were considered statistically significant. We also computed the intraclass correlation coefficient (ICC), which provided the variation percentage of variation due to the contextual level, and proportional change in variance $(\mathrm{PCV})$ of using the pill or a condom across the municipalities for Models 1 and 2. The PCV allowed us to assess the percentage change in the outcome variables attributed to the set of independent variables included in the models.

\section{Ethics}

The Research Ethics Committees of each of the 26 states and the Federal District approved the study. Permission to conduct the study was obtained from all State and local Departments of Education and from all schools. All adolescents signed an informed assent form, and their parents signed a consent form.

\section{Results}

\section{Characteristics of study participants}

Adolescent females who participated in the study were mainly non-white, attending public schools, not working in paid jobs, and were living with their mother or both parents. Almost half had their first sexual intercourse at the age of 14 years or earlier. The majority reported using condoms (65.3\%) at the last sexual intercourse, while only one out of five (29.1\%) reported using pill (Table 1 ).

\section{Context-level characteristics}

Brazilian State capitals are very diverse: population varied from 228,000 in Palmas, in the North, to more than 11 million in São Paulo, located in the southeast region. The coverage of primary healthcare teams varied from $27.4 \%$ in São Paulo to $100.0 \%$ in Vitória. Capitals with the highest proportion of antenatal care visits were Curitiba and Vitória ( $88.1 \%$ and $78.9 \%$, respectively) while in Macapá and Porto Velho, only $33.8 \%$ and $34.6 \%$ of newborns had more than seven antenatal care visits. MMR varied from 27.81 deaths per 100,000 women in Palmas to 165.70 in Belém (Table 2).

\section{Individual- and context-level factors associated with pill or condom use}

There was a wide variation in the use of pill among female adolescents across capitals, ranging from $4.8 \%$ in Macapá to $47.9 \%$ in Porto Alegre (data not shown in table). Results from the fully adjusted model showed that MMR and antenatal care coverage were significantly associated with use of pill during the last sexual intercourse among female adolescents. At the municipality level, higher MMR was inversely associated with using pills while higher antenatal coverage was positively associated with use of the method during the last sexual intercourse. The coverage of primary healthcare teams was not significantly associated with using pills. At the individual level, older adolescents, non-whites, those working in paid jobs, those living with no parents, and those whose mothers had medium or high educational level were significantly more likely to use pill compared with the respective sub-groups of adolescents.

In the null model, the ICC showed that approximately $9.7 \%$ of the total variance on the use of pill was attributed to municipality level and $90.3 \%$ to individual level factors. The inclusion of individual-level variables explained $10.2 \%$ of the context-level variance (Model 1). In Model 2 , the PCV showed that $64.9 \%$ of the variance at the municipality level were credited to the individual and contextual variables related to pill use (Table 3).

The use of a condom ranged from $50.1 \%$ in João Pessoa to $77.5 \%$ in Macapá (data not shown in table). No contextual variable was significantly associated with use of condom in the unadjusted model. In the null model, the ICC showed that approximately $2.7 \%$ of the total variance in condom use was attributed to municipality level and 97.3\% to individual level factors. Given such a low ICC, the full-adjusted model with the context-level variable was not estimated. Results from the model adjusted for individual-level factors showed that older adolescents, non-white, and those living with no parents were significantly less likely to use a condom, while those who had first sexual intercourse at age 15 or older were significantly more likely to use a condom compared with the respective comparison sub-groups (Table 4).

\section{Discussion}

This study presents new insights regarding the association between health indicators and use of contraceptives among female adolescents from cities of a middle-income country with advanced primary health care services but high levels of social inequality [23]. Specific interventions to promote the use of contraceptives that have proven effective include training providers in adolescent contraceptive counseling, providing free or over-the-counter contraceptives for adolescents, and making health services adolescent or youth-friendly [31-33]. Our findings suggest that the context in which adolescents live also matter for use of certain contraceptive methods. The findings, for instance, show that living in a municipality with low MMR or a high number of antenatal visits is positively associated with use of pills among female adolescents. 
Table 1 Distribution of female adolescents who had ever had sexual intercourse, and used pill or condom at last sex by background characteristics

\begin{tabular}{|c|c|c|c|}
\hline \multirow[t]{2}{*}{ Variables } & \multirow{2}{*}{$\begin{array}{l}\text { Ever had sexual intercourse } \\
(\mathrm{n}=7415) \\
\%(95 \% \mathrm{Cl})\end{array}$} & \multirow{2}{*}{$\begin{array}{l}\text { Used pill at last sex }(n=1629) \\
\%(95 \% \mathrm{Cl})\end{array}$} & \multirow{2}{*}{$\begin{array}{l}\text { Used condom at } \\
\text { last sex }(n=4841) \\
\%(95 \% C l)\end{array}$} \\
\hline & & & \\
\hline \multicolumn{4}{|l|}{ Age } \\
\hline 12 & $1.5(1.2-2.0)$ & $0.4(0.1-1.1)$ & $1.7(1.2-2.3)$ \\
\hline 13 & $4.6(4.0-5.4)$ & $1.8(1.1-2.8)$ & $5.3(4.4-6.3)$ \\
\hline 14 & $12.0(10.8-13.2)$ & $6.6(4.9-8.7)$ & $13.2(11.7-14.7)$ \\
\hline 15 & $21.2(19.8-22.7)$ & $16.8(13.9-19.8)$ & $22.1(20.1-24.1)$ \\
\hline 16 & $28.0(26.4-29.5)$ & $31.6(27.6-36.0)$ & $22.8(26.2-29.4)$ \\
\hline 17 & $32.7(31.0-34.4)$ & $43.0(37.3-48.9)$ & $30.0(28.4-31.9)$ \\
\hline \multicolumn{4}{|l|}{ Skin color } \\
\hline White & $33.5(31.4-35.6)$ & $44.1(39.0-49.4)$ & $33.7(31.5-35.9)$ \\
\hline Non-white & $66.5(64.4-68.5)$ & $55.9(50.6-61.0)$ & $66.3(64.1-68.5)$ \\
\hline \multicolumn{4}{|l|}{ Type of school } \\
\hline Public & $84.5(78.8-88.8)$ & $76.5(63.3-86.0)$ & $86.1(82.5-89.0)$ \\
\hline Private & $15.5(11.2-21.2)$ & $23.5(13.9-36.7)$ & $13.9(11.0-17.5)$ \\
\hline \multicolumn{4}{|l|}{ Worked in paid jobs } \\
\hline No & $69.5(67.7-71.2)$ & $63.0(58.6-67.2)$ & $70.2(68.0-72.2)$ \\
\hline Yes & $30.5(28.8-32.3)$ & $37.0(32.7-41.4)$ & $29.8(27.7-32.0)$ \\
\hline \multicolumn{4}{|c|}{ Living arrangements with parents } \\
\hline Living with both & $42.2(40.5-43.7)$ & $40.0(36.5-43.6)$ & $43.6(41.8-45.5)$ \\
\hline Living with mother & $42.3(40.7-43.9)$ & $43.8(39.4-48.2)$ & $40.9(38.8-43.0)$ \\
\hline Living with father & $4.6(4.0-5.4)$ & $4.9(3.6-6.8)$ & $5.0(4.1-6.0)$ \\
\hline Living with none & $10.9(9.8-12.2)$ & $11.3(8.5-14.8)$ & $10.5(5.2-11.9)$ \\
\hline \multicolumn{4}{|c|}{ Maternal educational level } \\
\hline Unknown & $21.5(19.2-24.1)$ & $15.5(11.3-21.0)$ & $21.1(19.1-23.1)$ \\
\hline Low & $21.1(19.4-22.8)$ & $18.8(16.2-21.7)$ & $22.0(20.1-24.0)$ \\
\hline Middle & $39.1(37.0-41.2)$ & $42.4(36.1-49.1)$ & $38.1(36.0-40.3)$ \\
\hline High & $18.3(16.5-20.3)$ & $23.2(19.0-28.1)$ & $18.8(16.8-21.1)$ \\
\hline \multicolumn{4}{|l|}{ Age at first sex } \\
\hline Up to 14 & $49.3(47.4-51.1)$ & $44.3(40.6-48.0)$ & $47.6(45.3-49.9)$ \\
\hline 15 or older & $50.7(48.9-52.6)$ & $55.7(52.0-59.4)$ & $52.4(50.1-54.7)$ \\
\hline
\end{tabular}

Our findings are consistent with those of a European study which found that geographical differences in adolescent pill and condom use could be explained by diverse access to reproductive health services and contraceptive supplies [10]. Certainly, in countries where there is high MMR, there is low prenatal care coverage and limited access to contraceptives [34]. Consequently, general investments in maternal health may result in improvements in the uptake of some family planning methods among adolescents as initiatives dedicated to women in general, not adolescent-specific, seem to influence contraceptive usage.

Adolescents could therefore benefit from improvements in reproductive health services that expand availability and access to contraceptives in primary healthcare facilities. Access to pills, especially where there are restrictions on contraceptive methods available to adolescents, is likely to contribute to prevention of unintended pregnancies and associated adverse health and socio-economic outcomes among this subset of the population. This is especially relevant because worldwide trends show that adolescent fertility rates in Latin America are the second highest in the world [35] and that Latin America is the only region where unintended pregnancies resulting in birth, as a proportion of all births, have increased [36], with limited progress in reducing adolescent pregnancy in the region.

The consequences of unintended pregnancies among adolescents are even worse compared with adult women because the adverse social and economic consequences 
Table 2 Characteristics of municipalities in Brazil, 2013-2014

\begin{tabular}{|c|c|c|c|c|c|}
\hline Macro-regions & State capitals & Population 2010 & $\begin{array}{l}\text { Coverage of primary } \\
\text { health care teams } 2014 \\
(\%)\end{array}$ & $\begin{array}{l}\text { Newborns whose mothers made more } \\
\text { than } 7 \text { antenatal care visits } 2013(\%)\end{array}$ & $\begin{array}{l}\text { Maternal mortality } \\
\text { rate (adjusted) } 2013\end{array}$ \\
\hline \multirow[t]{7}{*}{ North } & Belém & $1,393,399$ & 45.5 & 62.5 & 165.70 \\
\hline & Boa Vista & 284,313 & 67.6 & 50.7 & 42.30 \\
\hline & Macapá & 398,204 & 83.9 & 33.8 & 112.62 \\
\hline & Manaus & $1,802,014$ & 52.3 & 41.6 & 90.30 \\
\hline & Palmas & 228,332 & 82.2 & 63.0 & 27.81 \\
\hline & Porto Velho & 428,527 & 61.9 & 34.6 & 105.30 \\
\hline & Rio Branco & 336,038 & 91.7 & 48.2 & 56.20 \\
\hline \multirow[t]{9}{*}{ Northeast } & Aracaju & 571,149 & 82.6 & 54.6 & 53.34 \\
\hline & Fortaleza & $2,452,185$ & 44.4 & 51.1 & 65.18 \\
\hline & João Pessoa & 723,515 & 88.0 & 62.7 & 127.92 \\
\hline & Maceió & 932,748 & 49.7 & 50.7 & 79.67 \\
\hline & Natal & 803,739 & 64.1 & 57.1 & 56.70 \\
\hline & Recife & $1,537,704$ & 58.4 & 56.7 & 60.41 \\
\hline & Salvador & $2,675,656$ & 34.8 & 51.3 & 88.41 \\
\hline & São Luís & $1,014,837$ & 40.8 & 43.7 & 93.67 \\
\hline & Teresina & 814,230 & 84.8 & 56.4 & 50.28 \\
\hline \multirow[t]{4}{*}{ Southeast } & Belo Horizonte & $2,375,171$ & 94.2 & 76.8 & 38.24 \\
\hline & Rio de Janeiro & $6,320,446$ & 50.7 & 71.7 & 76.43 \\
\hline & São Paulo & $11,253,503$ & 27.4 & 75.1 & 45.67 \\
\hline & Vitória & 327,801 & 100.0 & 78.9 & 28.83 \\
\hline \multirow[t]{3}{*}{ South } & Curitiba & 1.751 .907 & 60.6 & 88.1 & 32.09 \\
\hline & Florianópolis & 421,240 & 96.5 & 70.9 & 47.70 \\
\hline & Porto Alegre & $1,409,351$ & 69.1 & 74.1 & 40.83 \\
\hline \multirow[t]{4}{*}{ Mid-West } & Brasíliaa $^{a}$ & $2,570,160$ & 55.4 & 69.5 & 72.39 \\
\hline & Campo Grande & 786,797 & 61.4 & 69.1 & 88.27 \\
\hline & Cuiabá & 551,098 & 52.4 & 70.3 & 29.63 \\
\hline & Goiânia & $1,302,001$ & 57.5 & 70.2 & 42.68 \\
\hline
\end{tabular}

${ }^{a}$ Federal District

may overlap with the adverse health outcomes [37]. Although the pill is a short-acting method whose effectiveness is highly dependent on user self-discipline, which can be problematic to adolescents, it provides a safe and effective way of preventing unintended pregnancies when taken correctly [38, 39]. Given that oral contraceptives are mainly obtained at commercial drugstores in Brazil, it could be that investments in reproductive health services would not make a difference for adolescents' access to the method. However, the purchase of oral contraceptives is more frequent among high- than low-income women [40], which means that most vulnerable adolescents still rely on primary healthcare services to obtain contraceptives, and are likely to take advantage of any enhancement on the quality of reproductive health services.

Although our findings show individual-level variations in condom use, much of the variation in use among the municipalities remains unexplained, which is inconsistent with findings from other studies which showed that contextual factors, such as gross domestic product, population growth and Human Development Index are correlated with condom use [13, 14]. This could reflect the fact that condoms are widely available in primary healthcare facilities in Brazil, along with other interventions concerning HIV/AIDS prevention, such as rapid testing and community-based health education programs. Besides being offered in primary healthcare facilities, pharmacies and drug stores, condoms are also available nationwide at low cost or even for free in a range of non-traditional outlets such as metro stations, grocery stores, supermarkets, convenience stores, nightclubs and during popular festivals, like carnivals. Context-level influence on adolescent condom use remains a gap to be addressed in future studies.

The male condom is effective against HIV and costeffective for HIV control and prevention, but its consistent use for prolonged periods remains low, especially 
Table 3 Odds ratios from multilevel logistic regression analysis examining the association between individual- and context-level factors and use of pill at last sexual intercourse among female adolescents in Brazil, 2014

\begin{tabular}{|c|c|c|c|c|}
\hline Variables & Null model & $\begin{array}{l}\text { Unadjusted model OR } \\
(95 \% \mathrm{Cl})\end{array}$ & Model 1 OR $(95 \% \mathrm{Cl})$ & Model 2 OR $(95 \% \mathrm{Cl})$ \\
\hline \multicolumn{5}{|l|}{ Individual level } \\
\hline Age & & $1.33(1.24-1.42)$ & $1.33(1.24-1.44)$ & $1.34(1.24-1.45)$ \\
\hline \multicolumn{5}{|l|}{ Skin color } \\
\hline White & & 1 & 1 & 1 \\
\hline Non-white & & $0.71(0.61-0.84)$ & $0.77(0.65-0.90)$ & $0.77(0.65-0.90)$ \\
\hline \multicolumn{5}{|l|}{ Type of school } \\
\hline Public & & 1 & 1 & 1 \\
\hline Private & & $1.55(1.18-2.02)$ & $1.26(0.96-1.66)$ & $1.26(0.96-1.66)$ \\
\hline \multicolumn{5}{|l|}{ Worked in paid jobs } \\
\hline No & & 1 & 1 & 1 \\
\hline Yes & & $1.26(1.12-1.42)$ & $1.21(1.07-1.38)$ & $1.21(1.07-1.38)$ \\
\hline \multicolumn{5}{|l|}{ Age at first sex } \\
\hline Up to 14 & & 1 & 1 & 1 \\
\hline 15 or older & & $1.19(0.99-1.43)$ & $0.86(0.68-1.07)$ & $0.86(0.68-1.07)$ \\
\hline \multicolumn{5}{|l|}{ Living arrangements with parents } \\
\hline Living with both & & 1 & 1 & 1 \\
\hline Living with mother & & $1.10(0.78-1.56)$ & $1.25(0.87-1.80)$ & $1.25(0.87-1.80)$ \\
\hline Living with father & & $1.06(0.87-1.29)$ & $1.09(0.89-1.34)$ & $1.09(0.89-1.34)$ \\
\hline Living with none & & $1.40(1.04-1.87)$ & $1.47(1.10-1.96)$ & $1.47(1.10-1.96)$ \\
\hline \multicolumn{5}{|l|}{ Maternal educational level } \\
\hline Low & & 1 & 1 & 1 \\
\hline Medium & & $1.49(1.17-1.91)$ & $1.39(1.07-1.81)$ & $1.39(1.07-1.81)$ \\
\hline High & & $2.10(1.53-2.87)$ & $1.85(1.32-2.57)$ & $1.85(1.32-2.57)$ \\
\hline \multicolumn{5}{|l|}{ Municipality level } \\
\hline \multicolumn{5}{|l|}{ Primary health care teams coverage } \\
\hline 1st tertile & & 1 & & 1 \\
\hline 2nd tertile & & $1.12(0.69-1.81)$ & & $0.85(0.57-1.27)$ \\
\hline 3rd tertile & & $1.31(0.74-2.32)$ & & $0.85(0.52-1.40)$ \\
\hline \multicolumn{5}{|l|}{ Antenatal care visits } \\
\hline 1st tertile & & 1 & & 1 \\
\hline 2nd tertile & & $1.81(1.19-2.76)$ & & $1.64(1.20-2.21)$ \\
\hline 3rd tertile & & $2.97(1.84-4.78)$ & & $1.89(1.32-2.70)$ \\
\hline \multicolumn{5}{|l|}{ maternal mortality rate } \\
\hline 1st tertile & & 1 & & 1 \\
\hline 2nd tertile & & $0.58(0.42-0.79)$ & & $0.71(0.52-0.98)$ \\
\hline 3rd tertile & & $0.38(0.22-0.64)$ & & $0.55(0.34-0.87)$ \\
\hline Total variance (SE) & $0.354(0.118)$ & & $0.318(0.104)$ & $0.124(0.037)$ \\
\hline ICC & 0.097 & & & \\
\hline Proportional change in variance (PCV) & & $10.2 \%$ & $64.9 \%$ & \\
\hline
\end{tabular}

Model 1: adjusted for all individual-level variables. Model 2: adjusted for individual-level and municipality-level variables

because of low-risk perception, non-intention of use, the need to negotiate its use with every partner, the belief that condoms reduce sexual pleasure, and use of alcohol and drugs [4, 7]. Furthermore, although our findings show that condom is used more frequently than pill, such use may be temporary and inconsistent. Literature shows that adolescents switch from condoms to pills or other contraceptive as they age and change relationships from casual to more steady and regular partners [41, 42]. The frequency of contraceptive transitions among adolescents suggest a need for health professionals to actively support the consistent use of condoms by adolescents whether 
Table 4 Odds ratios from multilevel logistic regression analysis examining the association between individual- and context-level factors and condom use at last sexual intercourse among female adolescents in Brazil, 2014

\begin{tabular}{|c|c|c|c|}
\hline Variables & Null model & Unadjusted model OR $(95 \% \mathrm{Cl})$ & Model 1 OR $(95 \% \mathrm{Cl})$ \\
\hline \multicolumn{4}{|l|}{ Individual level } \\
\hline Age & & $0.91(0.86-0.96)$ & $0.83(0.77-0.89)$ \\
\hline \multicolumn{4}{|l|}{ Skin color } \\
\hline White & & 1 & 1 \\
\hline Non-white & & $0.80(0.69-0.93)$ & $0.83(0.72-0.96)$ \\
\hline \multicolumn{4}{|l|}{ Type of school } \\
\hline Public & & 1 & 1 \\
\hline Private & & $1.32(1.07-1.63)$ & $1.11(0.89-1.39)$ \\
\hline \multicolumn{4}{|l|}{ Worked in paid jobs } \\
\hline No & & 1 & 1 \\
\hline Yes & & $0.89(0.78-1.00)$ & $0.94(0.82-1.07)$ \\
\hline \multicolumn{4}{|c|}{ Living arrangements with parents } \\
\hline Living with both & & 1 & 1 \\
\hline Living with mother & & $0.89(0.69-1.14)$ & $0.88(0.68-1.13)$ \\
\hline Living with father & & $0.87(0.74-1.01)$ & $0.87(0.75-1.01)$ \\
\hline Living with none & & $0.75(0.61-0.92)$ & $0.79(0.64-0.97)$ \\
\hline \multicolumn{4}{|c|}{ Maternal educational level } \\
\hline Low & & 1 & 1 \\
\hline Medium & & $0.98(0.72-1.33)$ & $0.96(0.70-1.32)$ \\
\hline High & & $1.25(0.97-1.62)$ & $1.15(0.85-1.56)$ \\
\hline \multicolumn{4}{|l|}{ Age at first sex } \\
\hline Up to 14 & & 1 & 1 \\
\hline 15 or older & & $1.35(1.16-1.56)$ & $1.61(1.36-1.91)$ \\
\hline \multicolumn{4}{|l|}{ Municipality level } \\
\hline \multicolumn{4}{|c|}{ Primary health care teams coverage } \\
\hline 1st tertile & & 1 & \\
\hline 2nd tertile & & $1.17(0.91-1.51)$ & \\
\hline 3rd tertile & & $1.19(0.90-1.57)$ & \\
\hline \multicolumn{4}{|l|}{ Antenatal care visits } \\
\hline 1st tertile & & 1 & \\
\hline 2nd tertile & & $0.80(0.59-1.09)$ & \\
\hline 3rd tertile & & $0.84(0.63-1.13)$ & \\
\hline \multicolumn{4}{|c|}{ Maternal mortality rate } \\
\hline 1st tertile & & 1 & \\
\hline 2nd tertile & & $1.00(0.77-1.30)$ & \\
\hline 3rd tertile & & $1.10(0.80-1.52)$ & \\
\hline Total variance (SE) & $0.091(0.022)$ & & $0.100(0.256)$ \\
\hline ICC & 0.027 & & \\
\hline
\end{tabular}

Model 1: adjusted for all individual-level variables

during medical consultations or at schools, including dual contraceptive education, as condoms remain the best form of dual protection against STIs and unintended pregnancy.

Regarding the individual-level factors associated with contraceptive use, our results showed that older adolescents were more likely to use pill and they were less likely to use a condom than their younger counterparts.
Literature shows that as adolescents age, they increase the use of effective contraceptives [43], switching from condoms to pill or other highly effective methods. These patterns suggest that efforts to provide sexual education to adolescents, including information on contraception, should reach them in their early adolescence to enable them make healthy and conscious decisions about their own sexuality. 
Our findings show that non-white adolescents had lower probabilities of using contraception compared to white girls. The findings are similar to those of a study in the US which found low contraceptive use among Black and Hispanic adolescents [44]. Racial disparity in contraceptive use in Brazil reflects the vulnerability of black women to poor reproductive health outcomes, including obstetric complications and poor access to prenatal care $[45,46]$. Tailored interventions to account for such disparities are a public health priority in the country.

Our findings further show that adolescents with highly educated mothers were more likely to use pill, compared to those whose mothers had low levels of education, while maternal education had no significant association with condom use. Highly educated mothers may be more aware of highly effective contraception and may have a better approach to communicating such issues with their daughters compared to those with no or low levels of education [47]. Great progress has been made in expanding access to basic education in Brazil, but not every woman has benefited from these advances. Socioeconomic status and education levels continue to play an important role in the access to sexual and reproductive health services, including contraception and abortion [48], and this suggests a need for policies and programs to address such inequalities in the country.

The findings of this study further show that adolescents who were involved in paid work, and those who reported living with no parents were more likely to use pill compared to those who were not involved in paid work or who lived with their parents. Adolescents involved in paid work and those living with no parents may comprise girls who have some autonomy in social life, which provides freedom in sexual and contraceptive choices, especially considering that pill is mainly accessed in retail drugstores. Given that adolescents face many barriers such as lack of information and prejudice at unfriendly health services [6], many of them who work and have their own money prefer to buy their contraceptives themselves [49]. Similarly, adolescents who do not live with parents may be married, i.e., in stable relationships, and with some economic self-independence, which may enable them access pills.

The availability of condoms is essential, particularly in HIV-endemic areas or regions where incidence is high among young people, and oral contraceptives remain an effective form of contraception even for adolescents. However, girls should still be given an opportunity to choose a method among a wide variety of contraceptives, including LARCs; thus, the method mix in Brazil should be expanded for adolescents [31] as it is limited to short acting methods [18].

\section{Limitations}

Although a robust sample of nationally represented Brazilian adolescent females aged 12 to 17 years was used, the cross-sectional nature of the study does not allow making causal inferences regarding the relationship between the factors considered and pill use. Information concerning the partner, or their affective-love relationship, was not considered, but steady couples who use the pill might feel that condom use is unnecessary. Our main outcomes, pill or condom use, denote a fixed behavior reported from the last sexual intercourse, limiting the understanding of any trend of continuation or discontinuation of the method used. Additionally, our data was collected in 2014, but recent studies have shown that no significant changes in adolescent contraceptive use have occurred in Brazil [18]. However, contextual factors may have worsened due to the onset of the COVID-19 pandemic, with many disruptions to reproductive health services worldwide [50].

\section{Conclusion}

Our findings show that sexually experienced female adolescents from municipalities with low maternal mortality and high antenatal care coverage were significantly more likely to use pill during last sexual intercourse compared to those from municipalities with high maternal mortality and low antenatal care coverage. However, variations in condom use were only evident at the individual but not contextual level. The findings suggest that promoting the use of pill among female adolescents may require approaches for health system strengthening rather than those solely focused on individual attributes. We posit that adolescents residing in municipalities with effective maternal healthcare systems are more likely to access family planning counseling and contraceptive supplies, especially the pill, compared to those from municipalities with ineffective systems.

\section{Abbreviations \\ DATASUS: Information Technology Department of the Brazilian Public Health- care System; ERICA: Study of Cardiovascular Risks in Adolescents; ICC: Intraclass correlation coefficient; LARC: Long-acting reversible contraceptives; MMR: Maternal mortality rate; PCV: Proportional change in variance; STI: Sexually transmitted infection.}

\section{Supplementary Information}

The online version contains supplementary material available at https://doi. org/10.1186/s12905-021-01447-6.

Additional file 1. Adolescents' questionnaire.

Acknowledgements

Not applicable. 


\section{Authors' contributions}

ALVB and LSD analyzed the data. ALVB, LSD, ARRL and EF drafted the manuscript and revised it critically. All authors read and approved the final manuscript.

\section{Funding}

The ERICA study was supported by the Brazilian Ministry of Health (Science and Technology Department) and the Brazilian Ministry of Science and Technology (Financiadora de Estudos e Projetos/FINEP and Conselho Nacional de Pesquisa/CNPq) (Grants FINEP: 01090421, CNPq: 565037/2010-2 and 405009/2012-7). Although the funding agencies supported all field work, they did not influence the study design, data collection, and data analysis/interpretation in the writing of this manuscript.

\section{Availability of data and materials}

The datasets generated and/or analyzed during the current study are not publicly available due to regulations of the ERICA project. The data are available on request, which may be sent to alvilela@usp.br.

\section{Declarations}

\section{Ethics approval and consent to participate}

This study was approved by the University of Sao Paulo School of Nursing Research Ethics Board (number 350.486). All methods were performed in accordance with Brazilian guidelines. No administrative permissions were required to access and use the datasets as two of the authors are part of ERICA research team.

\section{Consent for publication}

Not applicable.

\section{Competing interests}

The authors declare that they have no competing interests.

\section{Author details}

${ }^{1}$ Public Health Nursing Department, School of Nursing, University of São Paulo, São Paulo, Brazil. ${ }^{2}$ School of Nursing, University of São Paulo, Avenida Doutor Enéas de Carvalho Aguiar, 419, São Paulo, SP 05403-000, Brazil. ${ }^{3}$ Faculty of Health Sciences, University of Tarapacá, Avenida 18 de Septiembre, 2222, 1000000 Arica, Chile.

Received: 26 Auqust 2020 Accepted: 6 August 2021

Published online: 19 August 2021

\section{References}

1. Darroch JE, Woog V, Bankole A, Ashford LS. Adding it up: costs and benefits of meeting the contraceptive needs of adolescents. New York: Guttmacher Institute; 2016. https://www.guttmacher.org/report/adding-it-meeting-contraceptive-needs-of-adolescents.

2. Kalamar A, Tunçalp $O$, Hindin M. Developing strategies to address contraceptive needs of adolescents: exploring patterns of use among sexually active adolescents in 46 low- and middle-income countries. Contraception. 2018;98(1):36-40.

3. Abma JC, Martinez GM. Sexual activity and contraceptive use among teenagers in the United States, 2011-2015. National Health Statistics Reports; no 104. Hyattsville, MD: National Center for Health Statistics. 2017. https://www.cdc.gov/nchs/data/nhsr/nhsr104.pdf.

4. Looze M, Madkour AB, Huijts T, Moreau N, Currie C. Country-Level gender equality and adolescents' contraceptive use in Europe, Canada and Israel: findings from 33 countries. Perspect Sex Reprod Health. 2019;51(1):43-53. https://doi.org/10.1363/psrh.12090.

5. Biddlecom A, Riley T, Darroch JE, Sully E, Kantorová V, Wheldon M. Future scenarios of adolescent contraceptive use, cost and impact in developing regions. New York: Guttmacher Institute, 2018, https:// www.guttmacher.org/report/adolescent-contraceptive-use-in-devel oping-regions.
6. Chandra-Mouli V, McCarraher DR, Phillips SJ, Williamson NE, Hainsworth G. Contraception for adolescents in low and middle income countries: needs, barriers, and access. Rep Health. 2014;11:1.

7. Grangeiro A, Ferraz D, Calazans G, Zucchi EM, Díaz-Bermúdez XP. The effect of prevention methods on reducing sexual risk for HIV and their potential impact on a large-scale: a literature review. Rev Bras Epidemiol. 2015;18(Suppl 1):43-62.

8. Doyle AM, Mavedzenge SN, Plummer ML, Ross DA. The sexual behaviour of adolescents in sub-Saharan Africa: patterns and trends from national surveys. Trop Med Int Health. 2012;17(7):796-807.

9. Kothari MT, Wang S, Head SK, Abderrahim N. Trends in Adolescent Reproductive and Sexual Behaviors. DHS Comparative Reports No. 29. Calverton, Maryland, USA: ICF International. 2012. https://www.dhspr ogram.com/pubs/pdf/CR29/CR29.pdf.

10. Godeau E, Gabhainn SN, Vignes C, Ross J, Boyce W, Todd J. Contraceptive use by 15-year-old students at their last sexual intercourse: results from 24 countries. Arch Pediatr Adolesc Med. 2008;162(1):66-73.

11. Darroch JE, Singh S, Frost JJ at al. Differences in teenage pregnancy rates among five developed countries: the role of sexual activity and contraceptive use. Fam Plann Perspect. 2003;33(6):244-50, 81

12. Neal S, Harvey C, Chandra-Mouli V, Caffe S, Camacho AV. Trends in adolescent first births in five countries in Latin America and the Caribbean: disaggregated data from demographic and health surveys. Reprod Health. 2018:15:146.

13. Lazarus JV, Moghaddassi M, Godeau E, Ross J, Vignes C, Ostergren PO, et al. A multilevel analysis of condom use among adolescents in the European Union. Public Health. 2009:123:138-44.

14. Benefo KD. Determinants of condom use in Zambia: a multilevel analysis. Stud Fam Plann. 2010:41(1):19-30.

15. Borges ALV, Fujimori E, Kuschnir MCC, Chofakian CBN, Moraes AJP, Azevedo GD et al. ERICA: sexual initiation and contraception in Brazilian adolescents. Rev Saúde Pública. 2016;50(Sup. 1):15s.

16. Felisbino-Mendes MS, Paula TF, Machado IE, Oliveira-Campos M, Malta DC. Analysis of sexual and reproductive health indicators of Brazilian adolescents, 2009, 2012 and 2015. Rev Bras Epidemiol. 2018; 21(Suppl 1):e180013.

17. Ponce de Leon RG, Ewerling F, Serruya S, Silveira MF, Sanhueza A, Moazzam A et al. Contraceptive use in Latin America and the Caribbean with a focus on long-acting reversible contraceptives: prevalence and inequalities in 23 countries. Lancet Glob Health. 2019;7(2):e227-e35.

18. Olsen JM, Lago TG, Kalckmann S, Alves MCGP, Escuder MML. Young women's contraceptive practices: a household survey in the city of São Paulo, Brazil. Cad. Saúde Pública. 2018;34(2):e00019617.

19. Vasconcellos MTL, Silva PLN, Szklo M, Kuschnir MCC, Klein CH, Abreu GA, et al. Sampling design for the Study of Cardiovascular Risks in Adolescents (ERICA). Cad Saúde Pública. 2015;31(5):921-30.

20. Bloch KV, Szklo M, Kuschnir MCC, Abreu GA, Barufaldi LA, Klein CH, et al. The study of cardiovascular risk in adolescents - ERICA: rationale, design and sample characteristics of a national survey examining cardiovascular risk factor profile in Brazilian adolescents. BMC Public Health. 2015:15:94-103.

21. Victora CG, Aquino EM, do Carmo Leal M, Monteiro CA, Barros FC, Szwarcwald CL. Maternal and child health in Brazil: progress and challenges. Lancet. 2011;377(9780):1863-1876.

22. Barros AJD, Victora CG, Horta BL, et al. Antenatal care and caesarean sections: trends and inequalities in four population-based birth cohorts in Pelotas, Brazil, 1982-2015. Int J Epidemiol. 2019;48(Suppl 1):i37-45.

23. Macinko J, Harris MJ. Brazil's Family Health Strategy—delivering community-based primary care in a Universal Health System. N Engl J Med. 2015:372(23):2177-81.

24. Dourado I, Medina MG, Aquino R. The effect of the Family Health Strategy on usual source of care in Brazil: data from the 2013 National Health Survey (PNS 2013). Int J Equity Health. 2016;15:151.

25. Tuncalp Ö, Pena-Rosas JP, Lawrie T, Bucagu M, Oladapo OT, Portela AGA WHO recommendation on antenatal care for a positive pregnancy experience-going beyond survival. BJOG. 2017:124(6):860-2.

26. Benova L, Tunçalp Ö, Moran AC, Campbell OMR. Not just a number: examining coverage and content of antenatal care in low-income and middle-income countries. BMJ Global Health. 2018;3(2):e000779. 
27. Brasil. Ministério da Saúde. Secretaria de Atenção à Saúde. Departamento de Atenção Básica. Atenção ao pré-natal de baixo risco. Brasília. Ministério da Saúde, 2012. http://bvsms.saude.gov.br/bvs/publicacoes/cadernos_ atencao_basica_32_prenatal.pdf.

28. World Health Organization. Time to respond: a report on the global implementation of maternal death surveillance and response. Geneva: WHO; 2016. https://apps.who.int/iris/bitstream/handle/10665/249524/ 9789241511230-eng.pdf? sequence $=1$.

29. Brasil. Ministério da Saúde. Saúde Brasil 2017: uma análise da situação de saúde e os desafios para o alcance dos objetivos de desenvolvimento sustentável. Brasília. Ministério da Saúde, 2018. http://bvsms.saude.gov. br/bvs/publicacoes/saude_brasil_2017_analise_situacao_saude_desaf ios_objetivos_desenvolvimento_sustetantavel.pdf.

30. Silva BGC, Lima NP, Silva SG, Antúnez SF, Seerig LM, Restrepo-Méndez MC, et al. Maternal mortality in Brazil from 2001 to 2012: time trends and regional differences. Rev Bras Epidemiol. 2016;19(3):484-93.

31. Gottschalka LB, Ortayli N. Interventions to improve adolescents' contraceptive behaviors in low- and middle-income countries: a review of the evidence base. Contraception. 2014;90:211-25.

32. Hindin MJ, Kalamar AM, Thompson T, Upadhyay UD. Interventions to prevent unintended and repeat pregnancy among young people in lowand middle-income countries: a systematic review of the published and gray literature. J Adolescent Health. 2016;59(3 Suppl):S8-15.

33. Upadhya K, Santelli J, Raine-Bennett T, Kottke M, Grossman D. Overthe-counter access to oral contraceptives for adolescents. J Adolescent Health. 2017;60(6):634-40

34. GBD 2015 Maternal Mortality Collaborators. Global, regional, and national levels of maternal mortality, 1990-2015: a systematic analysis for the Global Burden of Disease Study 2015. Lancet. 2016;388(10053):1775-1812.

35. United Nations. UN Department of Economic and Social Affairs. World Fertility Patterns 2015. New York; 2015. http://www.un.org/en/devel opment/desa/population/publications/pdf/fertility/world-fertilitypatter ns-2015.pdf.

36. Bearak J, Popinchalk A, Lkema L, Sedgh G. Global, regional, and subregional trends in unintended pregnancy and its outcomes from 1990 to 2014: estimates from a Bayesian hierarchical model. Lancet. 2018;6:e380-89.

37. Ganchimeg T, Mori R, Ota E, et al. Maternal and perinatal outcomes among nulliparous adolescents in low- and middle-income countries: a multicountry study. BJOG. 2013;120(13):1622-30.
38. Powell A. Choosing the right oral contraceptive pill for teens. Pediatr Clin N Am. 2017;64:343-58.

39. Patton GC, Sawyer SM, Santelli JS, Ross DA, Afifi R, Allen NB, et al. Our future: a Lancet commission on adolescent health and wellbeing. Lancet. 2016:387:2423-78.

40. Farias MR, Leite SN, Tavares NUL, Oliveira MA, Arrais PSD, Bertoldi AD, et al. Use of and access to oral and injectable contraceptives in Brazil. Rev Saude Publica. 2016;50(supl 2):14s.

41. Manlove J, Ryan S, Franzetta K. Contraceptive use patterns across teens' sexual relationships: the role of relationships, partners, and sexual histories. Demography. 2007:44(3):603-21.

42. Upadhyaya UD, Raifmana S, Raine-Bennett T. Effects of relationship context on contraceptive use among young women. Contraception. 2016;94:68-73.

43. Tripp J. Sexual health, contraception, and teenage pregnancy. BMJ. 2005;330(7491):590-3.

44. Witwer E, Jones RK, Lindberg LD. Sexual behavior and contraceptive and condom use among U.S. high school students, 2013-2017. New York: Guttmacher Institute, 2018. https://doi.org/10.1363/2018.29941.

45. Viellas EF, Domingues RMSM, Dias MAB, Gama SGN, Theme Filha MM, Costa JV, et al. Prenatal care in Brazil. Cad Saude Publica. 2014;30:S85-100.

46. Leal MC, Gama SGN, Pereira APE, Pacheco VE, Carmo CN, Santos RV. The color of pain: racial iniquities in prenatal care and childbirth in BrazilCad. Saude Publica. 2017;33(suppl 1):e00078816.

47. Commendador KA. Parental influences on adolescent decision making and contraceptive use. Pediatr Nurs. 2010;36(3):147-56, 70.

48. Diniz SG, d'Oliveira AFPL, Lanskyc S. Equity and women's health services for contraception, abortion and childbirth in Brazil. Reprod Health Matters. 2012;20(40):94-101.

49. Nyarko SH. Prevalence and correlates of contraceptive use among female adolescents in Ghana. BMC Women's Health. 2015;15:60.

50. UNFPA. United Nations Population Fund. Impact of COVID-19 on Family Planning: what we know one year into the pandemic. Technical note. New York: UNFPA, 2021. https://www.unfpa.org/sites/default/files/resou rce-pdf/COVID_Impact_FP_V5.pdf.

\section{Publisher's Note}

Springer Nature remains neutral with regard to jurisdictional claims in published maps and institutional affiliations.
Ready to submit your research? Choose BMC and benefit from:

- fast, convenient online submission

- thorough peer review by experienced researchers in your field

- rapid publication on acceptance

- support for research data, including large and complex data types

- gold Open Access which fosters wider collaboration and increased citations

- maximum visibility for your research: over $100 \mathrm{M}$ website views per year

At BMC, research is always in progress.

Learn more biomedcentral.com/submissions 